\title{
El laboratorio de la educación: Francisco J. Múgica en Tabasco y Michoacán
}

\section{Education as Laboratory: Francisco J. Múgica in Tabasco and Michoacán}

\author{
Daniar Chávez Jiménez \\ Universidad Nacional Autónoma de México \\ daniarc@yahoo.com \\ Rubén Darío Ramírez Sánchez \\ Universidad Nacional Autónoma de México \\ rubendarioıs@hotmail.com
}

DOI: I0.2490I/rehs.v40i16I.430

\section{(c) EY-NC}

El laboratorio de la educación: Francisco J. Múgica en Tabasco y Michoacán por Daniar Chávez Jiménez y Rubén Darío Ramírez Sánchez se distribuye bajo una Licencia Creative Commons Atribución-NoComercial 4.o Internacional.

Fecha de recepción: 25 de abril de 2018

Fecha de aprobación: II de diciembre de 2018

\section{RESUMEN:}

En este artículo se analizan las transformaciones que sufrió el sistema educativo del estado de Tabasco durante el gobierno del general Francisco J. Múgica (I915-I9I6). Se destaca la importancia de las reformas impulsadas en materia de reestructuración administrativa, en infraestructura y pedagógica, esta última desde el punto de vista de la educación racionalista, que culminaría con la puesta en marcha de la República Escolar, a través de la cual se buscó diseminar los valores revolucionarios, fomentar la autonomía municipal e impulsar la educación rural. También se abordan algunos cambios educativos que, durante su breve estancia como gobernador del estado de Michoacán, a principio de la década de los veinte, llevó a cabo en el estado, entre ellos, la restructuración administrativa de la universidad de la entidad y las normales rurales.

Palabras clave:

Educación, República Escolar, Constitución, Francisco J. Múgica. 


\section{ABSTRACT:}

This article analyzes the transformations that the educational system of the state of Tabasco underwent during the government of General Francisco J. Múgica (1915-1916), emphasizing the importance of the administrative, infrastructural and pedagogical reforms he promoted. The pedagogical reform is highlighted from the perspective of rationalist education, which culminated with the implementation of the "School Republic" that sought to disseminate revolutionary values and promote municipal autonomy and rural education. We also address certain educational changes that, during his brief time as governor of the state of Michoacán in the early r920s, General Múgica carried out in that state, including the administrative restructuring of the state university and the rural Teachers Training Colleges (Escuelas Normales).

Keywords:

Education, "School Republic", Constitution, Francisco J. Múgica.

\section{Introducción}

La presente investigación indaga los orígenes de la política educativa que imperó desde principios de la Revolución hasta casi finales del siglo XX en los planes y programas que fueron impulsados por los distintos gobiernos federales. Es nuestro propósito hacer una revisión del caso del general Francisco J. Múgica durante su gobierno en los estados de Tabasco (1915-1916) y Michoacán (I920-1922). La intención es observar las políticas educativas impulsadas por Múgica, con las cuales logró impactar en ciertas estructuras socioculturales y socioeconómicas de ambos estados. El texto también indaga la forma en la que sus administraciones influyeron en el desarrollo rural, en las políticas de reconstrucción de la economía local, en el fortalecimiento de los municipios y, en general, en el impulso de las ideas que habían emanado de la Revolución; muchas de ellas plasmadas en los artículos de la Constitución Política de los Estados Unidos Mexicanos durante el Constituyente de I9I6-I9I7, del cual Múgica también fue un miembro destacado..$^{\underline{T}}$

Durante la siguientes décadas, principalmente, desde la administración del general Plutarco Elías Calles, hasta la conclusión del proyecto de educación socialista del gobierno del general Lázaro Cárdenas, en I940, la educación supuso la consolidación de un proyecto sobre el que descansarían los pilares que soportarían el avance social y económico del país, así como los múltiples esfuerzos que hubo por reconstruir la industria nacional en las grandes ciudades; representó, también, los esfuerzos por estimular la producción y la modernización del campo mexicano y el desarrollo económico regional.

Durante los años cuarenta del siglo XX, bajo la administración de Manuel Ávila Camacho, el proyecto educativo seguiría un camino cada vez más marcado hacia el corporativismo, condensado en el llamado indigenismo institucionalizado, que sería la consecuencia natural de los 
proyectos educativos llevados a cabo en los años anteriores. Se daría fin a los esfuerzos por impulsar una verdadera transformación del campo mexicano y de los sectores más desprotegidos, se pararían los esfuerzos por fomentar un desarrollo económico integral y comunitario, y las políticas públicas burocratizarían los programas educativos de toda la segunda mitad del siglo XX (Chávez 2016).

Con todo y las transformaciones del régimen político de mediados del siglo, la educación siguió siendo, en el discurso político, el principal instrumento gubernamental con el cual, presumiblemente, se disminuiría la brecha entre ricos y pobres y se pacificaría al país. A través del Plan de los Once Años (durante los sexenios de Adolfo López Mateos y Gustavo Díaz Ordaz, I958-1970), como instrumento de planeación educativa, se propuso enfrentar los problemas de cobertura que generaba la explosión demográfica. Las políticas se centraron en aumentar la capacidad de atención a través de las escuelas de doble turno, ampliar el programa de infraestructura, que fue acompañado con el crecimiento de las escuelas normales, al fortalecimiento del programa de formación de profesores, así como la implementación de nuevos planes y programas de estudio en el nivel primaria, que se vieron reflejados en los nuevos libros de texto gratuitos (Latapí igg2, I6-Ig).

Para los setenta y principios de los ochenta, la política educativa se centró en consolidar la reforma curricular, incentivar el crecimiento de oportunidades en el nivel medio superior y superior a través de la educación tecnológica en los estados, aunque estos propósitos se vieron limitados por las severas crisis económicas que enfrentaron los gobiernos de esta época. No obstante estas limitaciones, la descentralización educativa permitió lograr la cobertura en el nivel primaria a través de la flexibilización del esquema escolar, el remplazo de planteles, la construcción de albergues y la capacitación de instructores comunitarios.

En la era neoliberal, aunque se le siguió atribuyendo a la educación una vocación resarcitoria de las deudas históricas con las clases marginales, las "reformas modernizadoras" transformaron los contenidos y revaloraron la función magisterial. Esto propició que la educación se ajustara a las necesidades del mercado global y abandonara su compromiso (nunca cabalmente cumplido) con las historias y necesidades nacionales y regionales que, durante el siglo XX, los defensores de la lucha revolucionaria habían propuesto como su máximo legado (Alcántara 2008, I52-I62).

Primeros pasos: Tabasco entre 1915 y 1916

En la primera década del siglo XX, en el ocaso del porfiriato, Tabasco era una gran estepa verde incomunicada con el centro del país, su población alcanzaba los i85 mil habitantes, que representaban el i.2 \% de la población nacional. La vida social tabasqueña se desarrollaba bajo los basamentos de una cultura caciquil, la cual fortalecía la acumulación de grandes extensiones de tierras en pocas manos y propiciaba que sólo el $0.85 \%$ de la población del estado poseyera alguna propiedad agrícola. Esta división social obligaba a que la mayoría de los tabasqueños se dedicaran al peonaje y vivieran en condiciones de miseria en las haciendas (Canudas I984; Torres y Romero I9g2). Bajo este dominio de clase se afianzó una oligarquía mestiza privilegiada que accedió a la educación profesional y a los cargos públicos, lo cual permitió que 
una gran cantidad de mujeres de clase media alta se formaran primordialmente como educadoras. En contraparte, un amplio segmento depauperado de mujeres que enfrentaban su doble condición marginal (ser mujeres y pobres), no tuvo acceso a ningún tipo de formación. Es por ello que para i9or más del $95 \%$ de los profesionistas eran hombres y poco menos del $5 \%$ eran mujeres, y la mayoría de ellas se desempeñaban en "profesiones secundarias", como maestras, farmacéuticas, parteras, etcétera (Torres y Romero ig92, 49-50).

Aunque en ese periodo se creó el Instituto Juárez (I879), a la postre el centro de educación superior más importante del estado, que dio vida a la Universidad Juárez Autónoma de Tabasco (UJAT), con el gobierno de Carlos Madrazo Becerra en I966, las escuelas particulares atendían a un amplio porcentaje de los estudiantes a quienes impartían educación tecnológica y mercantil con la finalidad de formarlos profesionalmente para "que contribuyeran al desarrollo del comercio" (Torres 200I, 4I). En paralelo, el gobierno creó la Escuela Normal del Estado en i904, donde se instruiría al profesorado que requería el gobierno estatal para atender la instrucción primaria, tarea a la que también se incorporaron escuelas y liceos particulares dirigidos por grupos evangélicos (principalmente presbiterianos) y católicos.

La educación religiosa tenía una función evangelizadora y se había expandido en la geografía estatal. Para cumplir tal tarea sus promotores consideraban que la mujer podía asumir a cabalidad esta función, ya que era "un factor fundamental en la transmisión de los valores morales, así como la reproducción de los valores religiosos" (Torres 200I, 44). Al mismo tiempo, modificaron los programas de estudio y "sustituyeron las materias de historia patria y geografía por economía doméstica, asimismo se enseñaban oficios referidos socialmente a ellas como costura, bordado y tejido" (Torres 200I, 44).

En este Tabasco clasista del porfiriato, los hacendados, comerciantes y jefes políticos conformaban una "estrecha oligarquía tropical" (Canudas ig84, 40), la cual era educada primordialmente en escuelas privadas; mientras tanto la mayoría de la población económicamente depauperada recibía los servicios educativos públicos en una pobre infraestructura que, debido a la precariedad de sus instalaciones, era inoperable. Estas carencias propiciaron el cierre de escuelas y ocasionaron que, en los albores del siglo XX, Tabasco sólo contara con 72 escuelas primarias y una escuela secundaria, donde había inscritos 2,653 alumnos: I,730 eran hombres y 923 mujeres (Torres 200I, 44).

Con la llegada a Tabasco de Francisco J. Múgica Velázquez (I884-1954) como representante del gobierno constitucionalista de Carranza, y en calidad de encargado militar, jefe político y gobernador provisional del estado, se esperaba que las condiciones de la infraestructura física y la formación de recursos humanos para la expansión de la educación tuviera un avance significativo. Desde la llegada de Múgica, el io de septiembre de I9I5, hasta su partida el i3 de septiembre de igi6 (separación del cargo que se da por la aspiración de éste por formar parte del Congreso Constituyente convocado por el Primer Jefe del Ejército Constitucionalista, Venustiano Carranza), Tabasco registró avances en materia de pacificación e infraestructura con lo que se buscó disminuir las desigualdades sociales. $\stackrel{\text { ? }}{ }$ 
Imagen I. Francisco J. Múgica en Veracruz en I9I5, poco antes de su llegada a Tabasco

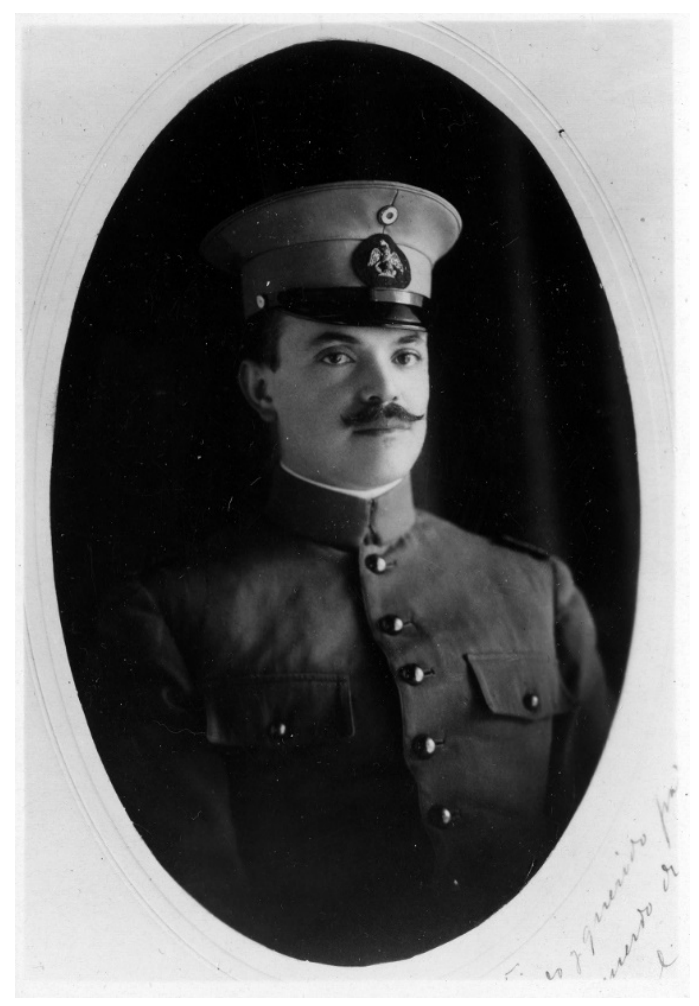

Fuente: Fototeca Francisco J. Múgica, caja 2, carpeta 3, foto 2.

En primer lugar, Múgica cumplió importantes tareas militares para pacificar el estado y castigar a los insurrectos villistas en la Chontalpa. En segundo lugar, emprendió una amplia transformación administrativa que inició con el reparto de tierras, así como la promulgación de la Ley Orgánica de la Administración que le permitió crear el Departamento Judicial, que puso en manos de Tomás Garrido Canabal. Ese nuevo andamiaje tuvo por objetivo limitar los abusos de poder y democratizar el acceso a los cargos públicos mediante elecciones, que deberían ser ocupados, preferentemente, por funcionarios jóvenes de origen tabasqueño, con lo cual iniciaría el relevo generacional del servicio público, hasta ese momento copado por viejos porfiristas (Núñez 2016, 49-IIq).

En este oleaje de cambios, las políticas educativas emprendidas por Múgica ocuparon un lugar primordial en su gobierno y abrieron nuevas expectativas para la reconstrucción del país bajo la directriz ideológica que imprimía el proyecto constitucionalista, núcleo de la narrativa del discurso revolucionario. La tarea educativa entonces se constituyó en uno de los retos más importantes del nuevo gobierno debido al arraigo que la tradición religiosa tenía en la idiosincrasia nacional que, de acuerdo con Múgica, era el principal obstáculo que había que "combatir y extirpar donde quiera que se les encuentre". ${ }^{3}$ Casi un año más tarde, durante el desarrollo de los debates del Constituyente, Múgica sería uno de los más voluntariosos defensores de las transformaciones del artículo $3^{\circ}$. 
Su carácter anticlerical lo ayudó a comprender la imposibilidad de conciliar las ideas revolucionarias con las ideas religiosas y lo impulsó a vislumbrar el importante papel que la educación tenía en la lucha de los distintos actores políticos y sociales del México de las primeras décadas del siglo XX:

Por ello, modificaron [los jacobinos] la libertad de enseñanza de la Constitución de 1857 , y establecieron la educación laica [...]. Por ello, desconocieron la personalidad jurídica de la Iglesia en el artículo rzo y consideraron indispensable acabar con el monopolio de la enseñanza en manos de aquélla. Para crear al nuevo Estado, emanado de la Revolución, se requería una enseñanza laica (Galeana 2017, 9).

No obstante, el pasado seminarista jacobino de Múgica, su estrecha relación con la educación rural heredada de su padre y abuelo, ayudaron a consolidar una ideología social, cuyos valores siguieron nutriendo su pensamiento anticlerical; ya al mando de la administración de Tabasco, combatiría a la religión y a los vicios sociales a través de sendas campañas antirreligiosa y antialcohólica que él mismo impulsó. ${ }^{4}$

La articulación de los esfuerzos gubernamentales tuvo como objetivo hacer de la enseñanza un instrumento de transformación social. Para ello fue necesario retornarle el sentido laico que ésta había perdido al quedar en manos de particulares y al margen de las disposiciones del gobierno estatal durante las administraciones anteriores. Adicionalmente, el gobierno inyectó recursos económicos por "un millón de pesos infalsificables", capital que representaba el 50 \% de todo el presupuesto del gobierno estatal para ese periodo, para operar el nuevo proyecto educativo, establecer una nueva infraestructura que permitiera expandir los servicios educativos a todos los tabasqueños y aumentar los bajos salarios de los escasos profesores que resultaban insuficientes para cubrir las necesidades educativas en el estado (María y Campos ig84, 9I).

Para Múgica, la educación era una tarea ideológica primordial y la creía "uno de los primeros deberes de la Revolución [porque además] cualquier movimiento social que no se preocupe por educar a su juventud, perecerá irremisiblemente" (Canudas 1984, 65). Por ello, hizo de la educación la principal vía para que las clases marginales tuvieran alternativas frente al control político y la explotación de los gobiernos porfiristas.

Durante el Constituyente, así como posteriormente a la formación de éste, el tema del laicismo en la educación fue relevante para los distintos gobiernos que tuvieron una amplia expectativa en la educación como pilar de las ideas revolucionarias y la propagación de las mismas en los distintos sectores, principalmente, los más desprotegidos social y económicamente, y los que se encontraban más alejados de las principales cabeceras municipales, con lo cual, la educación comenzó a enfocarse en el campo mexicano.

Años más tarde, explica Francisco Arce (2006), durante el gobierno de Plutarco Elías Calles (1924-1928), sería importante que la educación no sólo se pensara como una panacea universal en el sentido del desarrollo y la propagación a todos los sectores sociales de las ideas humanistas 
provenientes de la cultura occidental; era, ante todo, el instrumento que representaba la importancia de que "los campesinos hicieran producir la tierra, que los obreros se adiestraran en las técnicas modernas de producción y que el país saliera del caos económico en el que se encontraba" (p. I46). Progreso, modernización, uso de las ciencias, especialización de la técnica y, por tanto, bonanza económica y bienestar social se creyeron como una de las consecuencias inmediatas de la modernización del proceso educativo desde la perspectiva social que suministraban las ideas revolucionarias. ${ }^{5}$

La tarea educativa entonces buscaba materializar esas ideas emanadas de la lucha armada, llevarlas a lo más recóndito del estado, despojarlas del sentido mercantilista que la había convertido en un redituable negocio de particulares, hacer de ella una responsabilidad social y una misión histórica del Estado nacional (Canudas ig84, 67). Bajo esta convicción, la escuela se convirtió en el principal espacio de transformación social y en:

el vehículo eficaz por excelencia para la difusión de la enseñanza, la base firme que consolida la preponderancia de los principios y el medio más seguro para obtener la regeneración del pueblo, es ella por consecuencia la llamada a satisfacer las necesidades apuntadas y por lo mismo debe darse cabida a la educación cívica entre las materias inherentes a la enseñanza primaria (Múgica I985.77).

A dos meses de haber iniciado el gobierno de Múgica en Tabasco, se decretó la incorporación de las escuelas privadas al sistema oficial, así como la aplicación de los métodos modernos, con lo que el estado se hizo del control de la educación, y pudo aplicar las sanciones correspondientes a quienes no se sujetaron a las nuevas disposiciones, con multas que oscilaban entre los diez y cien pesos, o arresto de treinta días (Múgica I985, 58).

Para hacer operativos los cambios en la educación, por un lado, el gobierno de Múgica suprimió la Dirección General de Educación Primaria del estado, la cual se había constituido en un obstáculo operativo y económico para el gobierno estatal y la sustituyó por el Departamento de Educación Pública, dependiente de la Secretaría General de Despacho, desde donde ejercía la Dirección Técnica y Administrativa que le garantizaba tener el control directo de la política educativa. Por otro lado, propuso y apoyó la celebración del Congreso Pedagógico, el 28 de febrero de 1916, con el objetivo de debatir los problemas y "reorganizar la educación pública" (Torruco I988, 335). El congreso contó con la participación de destacados profesores tabasqueños de la talla de Rosenda Taracena Padrón, Gonzalo del Ángel Cortés, Athié Giorgana, Francisco J. Santamaría, Alfonso Caparroso, entre otros, y se convirtió en un espacio deliberativo que permitió discutir la unificación de los criterios y métodos pedagógicos. ${ }^{-}$ 
Imagen 2. Carta de Alfonso Caparroso a Múgica el 27 de abril de igi6 relacionada con el Congreso Pedagógico en Tabasco

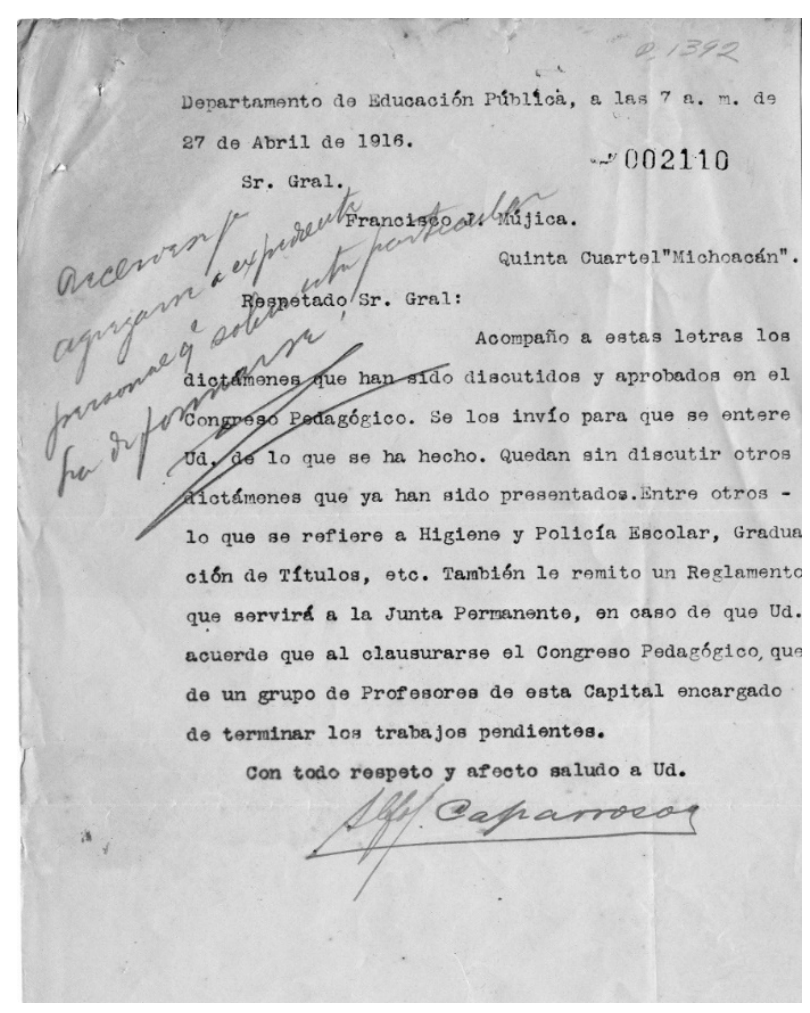

Fuente: Fondo Francisco J. Múgica. Documentación suelta, caja 6, carpeta 231, I392-I393.

La apertura de un espacio de discusión como éste propició un amplio debate sobre los rumbos que pedagógica y organizativamente debía tomar la educación en el estado. Los debates del Congreso Pedagógico mostraron la hegemonía masculina y la limitada visión que permeaba en los profesores sobre sus colegas tabasqueñas, al proponer que las maestras casadas debían ser cesadas del magisterio debido a que por su condición marital "no podían cumplir nunca con los deberes que reclama tanto el hogar como la escuela” (Torruco I988, 336). Este posicionamiento sexista y discriminatorio despertó una acalorada discusión con ríspidos intercambios entre los asistentes; sin embargo, concluyeron "que la maestra en estado de grávido se retire de la escuela con goce de sueldo hasta por cuatro meses, es decir, dos antes y dos después de su alumbramiento" (Torruco I988, 336).7

El Congreso Pedagógico permitió también analizar los principales problemas que enfrentaba la educación en Tabasco. El más preocupante fue la deficiente formación de los educadores. Para enfrentar el problema, el gobierno implementó un curso urgente de capacitación pedagógica durante un semestre, en el que se suspendieron las actividades docentes. Al mismo tiempo, el gobierno autorizó la compra de libros de texto y útiles.

La vigilancia del cumplimiento de los resolutivos del Congreso quedó a cargo del Consejo Superior de Educación, integrado por pedagogos tabasqueños que supervisaban la operatividad 
de los acuerdos y la puesta en marcha de la República Escolar, cuyo objetivo era incidir en la transformación de los niños y familiarizarlos con las prácticas cívicas, con los deberes ciudadanos y las responsabilidades públicas. De acuerdo con el proyecto educativo, esto permitiría "restablecer y asegurar para siempre la libertad de los ciudadanos", estimándose "imposible la realización de tan sublime ideal, mientras la mayoría del pueblo se encuentra sumida en la deplorable ignorancia de sus derechos [...] resulta indispensable proceder a la educación cívica del pueblo" (Múgica citado en Canudas 1984, 68). Se pretendía que en un periodo de tres años los estudiantes conocieran las cualidades y potencialidades del municipio libre (que para los ideales revolucionarios representaba la base de la democracia y, además, de la autonomía comunitaria) y los preceptos de la educación cívica, a través de la impartición de materias como El Municipio Libre, El Estado Soberano y La República (Múgica 1985. 78), entre otras asignaturas que destacaban el origen social del nuevo perfil educativo.

Para cumplir esta tarea, por un lado, el gobierno implementó un curso de preparación especial para profesores que no contaban con título y para quienes desearan dedicarse al magisterio; y, por otro, apoyó la formación agroproductiva, otorgando veinte becas a los alumnos más aventajados del Instituto Juárez que desearan cursar licenciaturas en el área de agricultura, así como diez becas más a jóvenes tabasqueños para estudiar en la Normal de Profesores y Agricultura de Yucatán. Con estos apoyos, Múgica buscó hacer efectiva la idea de que la transformación del estado dependía de la educación y del desarrollo de la agricultura con base en el conocimiento científico (Canudas rg84,69).

El pensamiento dialéctico y la formación revolucionaria del general Francisco J. Múgica permitieron solidificar y sintetizar su compromiso social. Esto le permitió entender que el estrecho vínculo entre la ignorancia y la marginación económica y social sólo se podía romper con los conceptos de libertad y educación, los cuales no se podían disociar. Esta conciencia de la realidad lo llevó a posicionarse en contra de lo que él llamaba el "fanatismo religioso", que consideraba uno de los mayores obstáculos para la formación educativa dialéctica y libertaria, retomada fundamentalmente del pedagogo ruso Antón Makárenko. Con este bagaje teórico, entendió que la prioridad del nuevo gobierno debía dirigirse a la formación de una sociedad igualitaria, y que una de sus tareas era abrir escuelas, cerrar cárceles y dar ejemplo de confraternidad y justicia.

Bajo estos principios, Múgica suprimió el Seminario Conciliar de Villahermosa donde se difundían ideas "oscurantistas y retardatarias" que iban en contra de los "sublimes ideales" revolucionarios sintetizados en el propósito de "elevar el nivel moral e intelectual del pueblo" (Múgica 1985.59). En su lugar estableció la Escuela de Artes y Oficios del Estado dedicada a la enseñanza básica y al cultivo de las artes y oficios en las clases populares, de manera especial a los huérfanos de los combatientes revolucionarios (Canudas 1984, 68 y María y Campos ig84. go). Múgica confiaba que en esta formación educativa sería determinante el temperamento del hombre del trópico, así como la fecundidad que la exuberancia natural otorgaba a los tabasqueños. 
Imagen 3. Memorándum del 9 de marzo de i9ı6, donde Múgica informa sobre la realización del Congreso Pedagógico de Tabasco y la confiscación de edificios clericales para espacios educativos

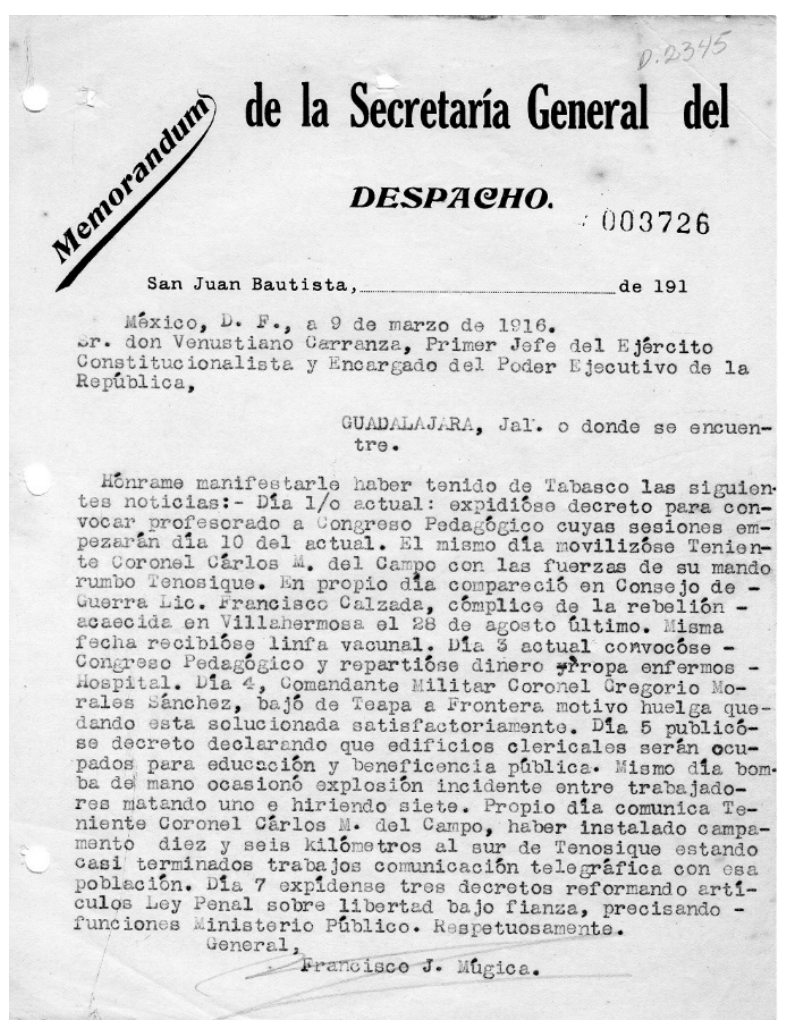

Fuente: Fondo Francisco J. Múgica, Documentación Suelta, caja 8, carpeta 262, documento 2345 .

Estableció también la Escuela de Música, con la cual buscaba incentivar la cultura general y las bellas artes por la función que éstas tienen en la vida de las sociedades modernas y el "entusiasmo de la vida nacional" (María y Campos 1984, 90). Asimismo, fundó la Escuela Vocacional para Señoritas, que bajo el auspicio de una educación racionalista ${ }^{\underline{8}}$ tuvo por objetivo formar culturalmente a la mujer, desarrollar en ella un espíritu de independencia que la alejara de "la vida vegetativa" y la preparara para la vida real. Esta formación permitiría a las mujeres combatir lo que Múgica consideraba fanatismos religiosos; dotarse de conocimientos para realizar su labor educadora; y cumplir una de las misiones sustanciales del gobierno revolucionario (Múgica 1985, 7I). El apoyo a la educación de la mujer tuvo resultados en el mediano plazo al celebrarse por primera vez un congreso feminista en Tabasco en 19I5, que se replicó en el garridismo unos años después (Torruco I988, 349; Moctezuma-Barragán 200I, 70). El evento permitió posesionar la discusión sobre la obra liberadora de la Revolución en la mujer, así como el lugar nodal y la función que ésta debía tener en el proceso revolucionario, que se materializó con el activismo que en el garridismo las mujeres emprenderían en defensa de sus derechos laborales, familiares y políticos; que ampliaría su participación en los asuntos públicos; y que, a la postre, daría el derecho al voto en 1925 (Torres 200I, gi). 
Las tareas formativas de la nueva sociedad en el gobierno constitucionalista en la entidad se centraban en la difusión de la cultura popular, en las manos del profesorado que, a consideración Alfonso Caparroso, jefe del Departamento de Educación Pública del Estado, entraban:

en un periodo de organización sólida, racional, metódica, firme y bien definida, que los pondrá en condiciones de ser útiles a la niñez, que se levanta y por ende a los ciudadanos del porvenir, y eleva el nivel intelectual y moral del maestro en la escala de la cultura nacional, armándolo para que pueda obtener, por el mismo su dignificación personal (María y Campos ig84, 92).

Así como el Congreso Pedagógico y las acciones subsecuentes en materia educativa permitieron que un sector minoritario de mujeres tabasqueñas diera "sus primeros pasos en un activismo", posteriormente el garridismo (en los tres periodos en los que estuvo a cargo de la administración del estado entre r9r9 y 1934) "pasaría del discurso pedagógico a la lucha por los derechos políticos y laborales" (Torres y Romero ig92, 2I). En efecto, el quehacer de las maestras tabasqueñas rendiría sus frutos en el gobierno de Tomás Garrido Canabal, donde se integraron a las tareas formativas bajo el modelo de educación racionalista, el cual las dotó de herramientas para replantear su condición laboral, familiar, su participación en la política y el gobierno que derivó en el derecho al voto (Torres 200I; Martínez-Assad 2004). La continuidad del modelo educativo racionalista puso énfasis en la formación del niño y el joven para beneficio de la comunidad a la que se encontraba integrado. Y la escuela se convirtió en el medio para comunicar a los sectores sociales sin discriminación y privilegios; siendo el talento, la probidad y la sabiduría las únicas jerarquías reconocidas por la Revolución. En este sentido, el quehacer educativo se dirigió a incentivar el ejercicio teórico práctico en las comunidades rurales ( $\underline{\mathrm{Muñoz}}$ I992, 47-50).

\section{Del Congreso Constituyente al gobierno de Michoacán (1920-1922)}

Tres meses después de la renuncia de Múgica al gobierno de Tabasco, durante los debates del Congreso Constituyente y ya convertido en diputado por el distrito de Zamora, Michoacán, el general pondría especial énfasis en el tema de la educación, a través de las modificaciones y los debates que se dieron en torno al artículo $3^{\circ}$. La libertad de enseñanza y la necesidad de concebir una educación laica, impartida por el Estado, se convirtió en materia de fervientes debates entre los diputados que manifestaban la necesidad de preponderar en esta materia la defensa de las libertades individuales por encima de las colectivas y los que sostenían lo contrario (José 2or7). La primera posición, por supuesto, como sucedió en la Constitución del 57, dejaba abiertas las puertas a la participación del clero en la impartición de la educación; la segunda, con la que comulgaba Múgica, priorizaba las libertades sociales sobre las individuales (esto, en cuanto se refiere estrictamente a la impartición de la educación), por lo que sólo la laicidad y la vigilancia del Estado podrían garantizar que el bien común y social imperara sobre el individual, como hoy sostiene la Constitución en su artículo $3^{\circ}$.

La experiencia administrativa que Múgica había tenido en Tabasco rendía sus frutos; el haber tenido al mando la transformación magisterial y docente del estado sureño del país, lo llevó a 
consolidar sus posicionamientos ideológicos, que trascendían los diálogos filosóficos o políticos, y se basaban en la experiencia directa; experiencia sustentada, además, en uno de los primeros modelos que habían impulsado la educación social bajo los principios que dictaban las ideas revolucionarias. Esas ideas revolucionarias también tuvieron un fuerte impacto en la aprobación de los artículos i23, sobre el trabajo y la prevención social, y el 27, sobre la propiedad de la tierra, el agua y el subsuelo, y los intereses de la nación, donde también Francisco J. Múgica participó activamente.

Años más tarde, durante su segunda campaña a la gubernatura por el estado de Michoacán, en I920, Múgica consideraría como bases de su plan de gobierno, las siguientes prerrogativas:

Fraccionamiento de los grandes latifundios, organización de los Comités Locales Agrarios, tramitación gratuita a las comunidades indígenas.

Reglamentar el Artículo r23 Constitucional a fin de hacer efectivas las garantías de dicho ordenamiento a los trabajadores.

Creación de escuelas tecno agrícolas en diversos municipios de la entidad y creación de escuelas rurales y nocturnas para los trabajadores jóvenes [...].

Ambos, el presidente y el gobernador, sustentan sus proyectos en la Constitución de I9I7 fundamentalmente en los artículos radicales, el 3 sobre educación, el 27 en torno a la propiedad de tierras y agua, el II5 sobre el municipio libre, legislación sobre el trabajo en el ı23 y el izo las leyes en materia de culto religioso (Bermejo I985, I23-I24). 
Imagen 4. El general Francisco J. Múgica con militantes del Partido Socialista

Michoacano. Toma posesión como gobernador (2I de septiembre de I920)

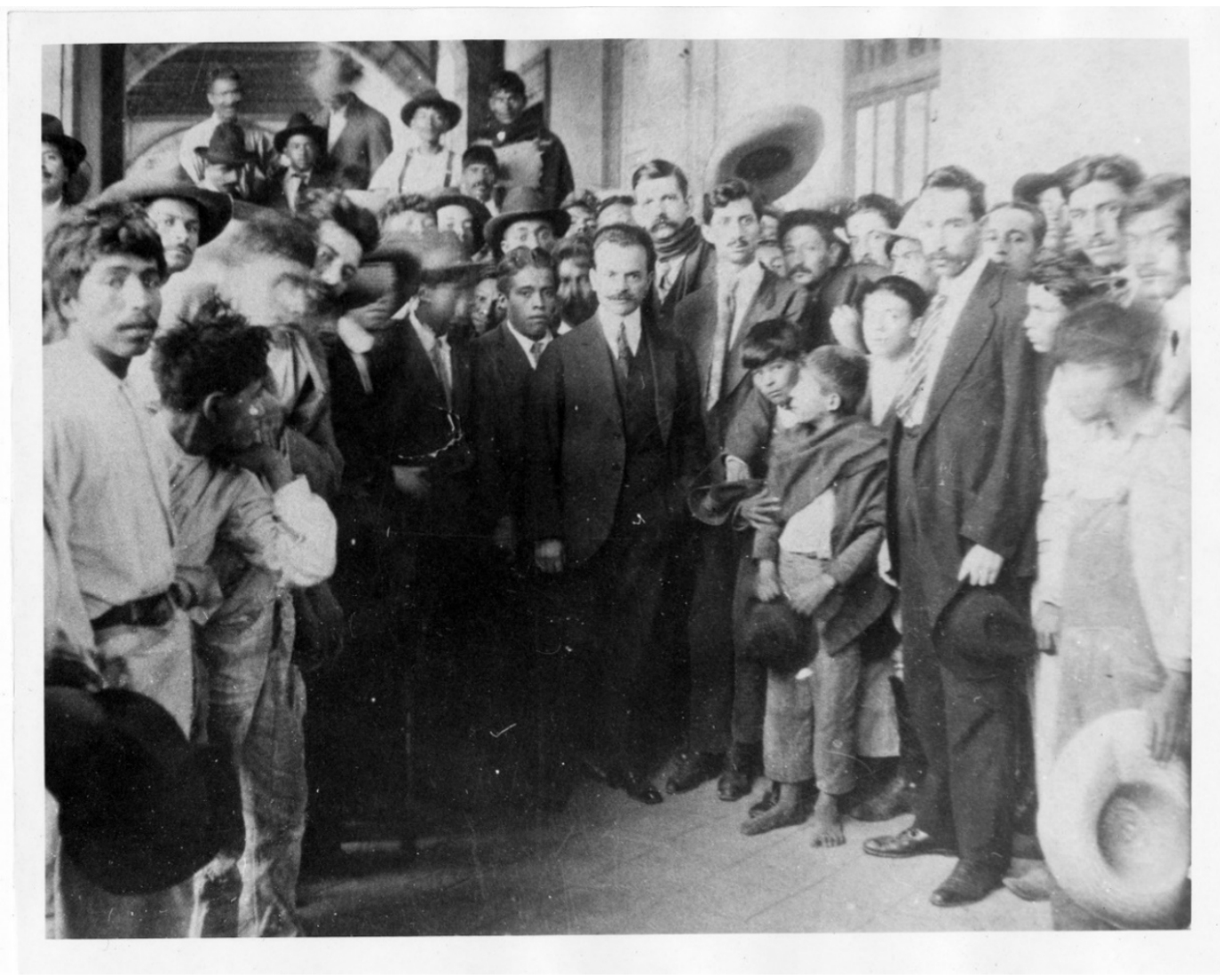

Fuente: Fototeca Francisco J. Múgica, caja 2, carpeta 5, foto I.

El proyecto educativo de Múgica, durante su gobierno en Michoacán, tal cual como había sucedido en Tabasco, se implementó como el instrumento que debía ayudarlo a reivindicar a las clases depauperadas y "sacarlas de la miseria y el oprobio a la que habían sido sometidas por los gobiernos dictatoriales para facilitar su explotación” (Canudas I984, 68). Múgica consideraba ineludible que la educación llegara a todos los ámbitos y rincones del estado, con lo cual daba seguimiento a una de las promesas más emblemáticas del movimiento revolucionario (que para muchos habían sido concluidas y cumplidas con la promulgación de la Constitución), cuyo objetivo ideológico era la construcción de un proyecto de Nación que permitiera reconstruir la paz en un contexto de conflicto y la gestación futura del "hombre nuevo", el cual emanaría de la educación fincada en las artes y el humanismo, donde el mundo rural representaba uno de los más importantes espacios para el cultivo y el quehacer de estas disciplinas.

Durante los veinte, y también durante el periodo de la educación socialista impulsado durante los treinta, principalmente, durante la administración cardenista:

La historia de la educación rural [...] puede verse pues, como parte del objetivo central del gobierno de reconstruir la economía del país. La expansión del 
sistema escolar en el campo [...] no fue solamente un intento por educar al campesino, sino un esfuerzo básico por organizar económicamente al agro y sentar las bases de un nacionalismo político (Arce 2006, 150-I5I).

En Michoacán, el gobierno de Múgica también se caracterizó por impulsar una transformación radical en la infraestructura del estado, que al igual que en Tabasco, se encontraba a punto del colapso. Por ejemplo, del monto total del presupuesto dedicado a la educación (que había aumentado considerablemente en el gobierno de Múgica con respecto a las administraciones anteriores), la mitad fue destinada al mantenimiento de planteles, "de escuelas industriales, de instrucción superior y sus organismos administrativos" (Rodríguez I985. 179).

Se inauguraron nuevos planteles, principalmente, en las zonas rurales más abandonadas, lo que hizo imperativo la contratación y capacitación de nuevos profesores que atendieran dichos espacios de formación escolar, al tiempo que se les duplicó el salario a todos los docentes de las escuelas públicas del estado. En I922 se creó la Normal Rural de Tacámbaro; un año antes en La Piedad Cabadas, se había fundado la Normal Regional Mixta; durante ese mismo periodo nacería la Escuela de Artes y Oficios (Rodríguez I985), proyectos encaminados a acompañar otras prerrogativas que formaban parte de los conceptos básicos de las ideas revolucionarias y de las garantías individuales que la Constitución Política de los Estados Unidos Mexicanos contenía en sus fojas y que, bajo la experiencia de Múgica durante su estancia en Tabasco, resultaban indispensables para echar a andar los proyectos sociales que su gobierno esgrimía.

En cuanto a la relación de la administración de Múgica con la universidad del estado, recientemente formada por uno de sus antecesores, Pascual Ortiz Rubio, en 1917, el gobierno estatal intentó supeditar la autonomía de la primera a la jurisdicción de la segunda, con el firme propósito de quitar el control a los viejos grupos conservadores, enquistados dentro de sus aulas y encauzar los nuevos derroteros de la universidad. Derogó las leyes que le otorgaban autonomía plena y la hizo depender de la autoridad estatal. Además, modificó muchas de las leyes constitutivas y removió a muchas de las autoridades; entre los nuevos rostros propuestos para impulsar las reformas universitarias destacaría la figura del joven médico Ignacio Chávez, ${ }^{q}$ que sería nombrado rector de I920 a I92I. 
Imagen 5. Carta de Ignacio Chávez a Francisco J. Múgica, I4 de marzo de I92r. El rector reconoce las convicciones y la actitud de Múgica hacia la educación universitaria en el estado

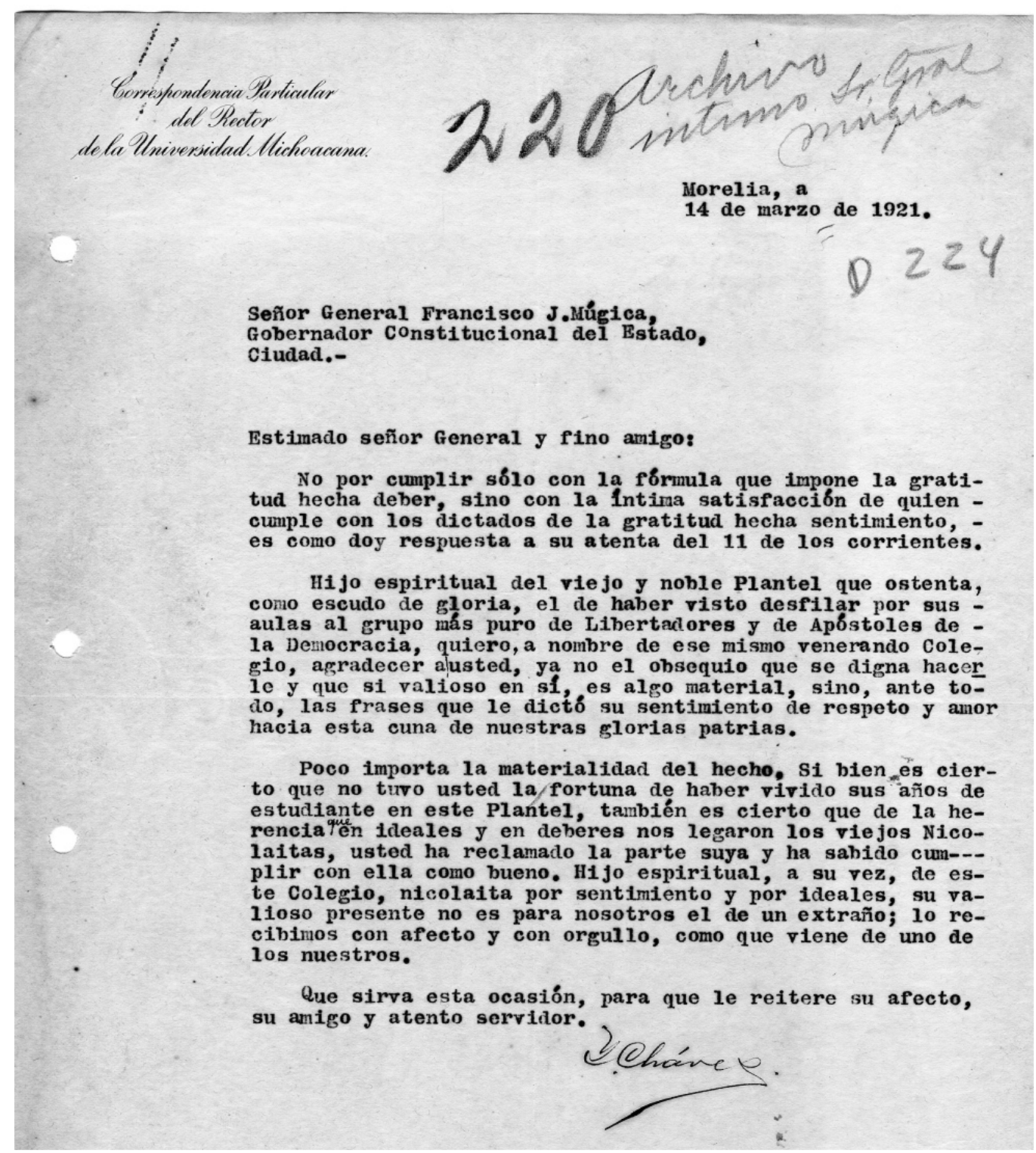

Fuente: Fondo Francisco J. Múgica, sección Tomos, caja I, tomo VIII, documento 224.

El hecho de que las escuelas normales dependieran de la universidad, aunado al fundamento de que el proyecto de trabajo del ejecutivo estatal descansaba en gran medida en la existencia de las escuelas normales y los planes de crear las normales rurales y las escuelas para trabajadores (con lo que se pretendía modernizar la estructura agraria y la economía rural del estado), que afectaba a intereses particulares y a grupos de poder universitarios, ocasionaron una fuerte ruptura entre Múgica (y el Partido Socialista Michoacano que lo impulsaba) y algunos sectores universitarios que eran apoyados por el Partido Liberal y los viejos grupos porfiristas 
(Hernández 1985) hacinados en la universidad michoacana. La ruptura de Múgica con las oligarquías y las fuerzas políticas, económicas, eclesiásticas y universitarias del estado, era más que evidente.

El lapso del gobierno de Múgica en Michoacán fue accidentado y concluyó abruptamente gracias a la presión que la burguesía local ponía en las autoridades federales, lo que obligó al gobernador en turno a renunciar al cargo para el que había sido electo por el voto popular. El argumento: "la tirantez a que han llegado las relaciones entre el ejecutivo que represento y el federal, tirantez que perjudica también a los demás poderes del estado, me impide continuar en el gobierno" (Múgica, citado en Rodríguez 1985, I80).

\section{Apuntes finales}

Como había sucedido en Tabasco casi seis años atrás, la visión de Múgica en Michoacán de cómo debía llevarse a cabo el reparto de la tierra; sostener las garantías laborales; impulsar la seguridad social; y echar a andar los proyectos educativos, no había sido bien recibida por las oligarquías locales que pretendían conservar sus privilegios.

A nivel nacional y durante el gobierno del general Plutarco Elías Calles, el intento por seguir vinculando el desarrollo económico a los proyectos educativos siguió vigente, pero tomaría otro derrotero cuando Moisés Sáenz comenzaría a ocuparse del proyecto educativo del Ejecutivo federal: "Él fue quien integró los diferentes programas en una gran estructura que incluía una concepción pedagógica y una noción de las metas a las que debía avocarse la educación nacional. Ideólogo y crítico de la educación callista, fue probablemente con Vasconcelos, el educador con la noción más ambiciosa del quehacer educativo mexicano" (Arce 2006, I52). Para Sáenz, la educación representaba el medio por el cual se lograría la integración nacional y, por consiguiente, también representaba el inicio del progreso social y político del país.

En los años de la persecución religiosa, el papel de la educación que intentaba implementar el Estado fue origen de violentas acusaciones y encarnizados dogmatismos entre los grupos liberales y conservadores. ${ }^{-0}$ Muchos sectores populares en algunos estados de la República, encabezados por la Iglesia católica, imploraban su derecho a educar a sus hijos bajo sus propias creencias religiosas y desconfiaban de la patria potestad que el Estado había esgrimido sobre la educación.

Durante el cardenismo y el periodo de la educación socialista, el panorama no había cambiado mucho, salvo, tal vez, por el poder de diálogo que pudo blandir el presidente Cárdenas con los sectores disidentes y contrarios a la educación rural, popular y socialista, y que luchaban por su derecho a poder impartir a sus hijos una educación religiosa. No obstante, el papel de la educación de corte social y la figura del aula siguieron teniendo un papel muy importante en la relación que existía entre los sectores populares y el Estado, y fue precisamente durante "la primavera de 1938 [que] los planteles fueron convertidos en centros de acopio, propaganda y apoyo [para] la expropiación petrolera" (Quintanilla), de la cual Francisco J. Múgica también 
fue un importante artífice, junto con los proyectos de reforma agraria, educación socialista y nacionalización de la industria que impulsaba el proyecto cardenista.

La educación social y popular nacida de la ideología revolucionaria llegaría a su fin junto con la conclusión del periodo de Cárdenas y la renuncia de Múgica a favor de Manuel Ávila Camacho en la carrera por ganar la candidatura a la presidencia de la República. Con el nuevo gobierno, el enfoque social de la educación se sintetizaría cada vez más en una política educativa fuertemente centralizada y burocratizada. El cambio de dirección del régimen era inminente y se explica por la necesidad que tenía el Estado mexicano por estabilizar la educación y pacificar socialmente al país.

\section{Archivo}

Fondo Francisco J. Múgica, Archivo Histórico de la Unidad Académica de Estudios Regionales, Coordinación de Humanidades, Universidad Nacional Autónoma de México, Jiquilpan de Juárez, Michoacán.

\section{Bibliografía}

ALCÁNTARA, Armando. 20o8. "Políticas educativas y neoliberalismo en México: i9822006". Revista Iberoamericana de Educación (48): I47-165.

ARCE GURZA, Francisco. 2006. "En busca de una educación revolucionaria (I824-I934)". En Ensayos sobre historia de la educación en México. Josefina Zoraida Vázquez et al. México: El Colegio de México, Centro de Estudios Históricos.

BERMEJO, Guillermo. 1985. "Múgica en el gobierno de Michoacán”. En VII Jornadas de Historia de Occidente, Francisco J. Múgica. México: Centro de Estudios de la Revolución Mexicana.

CANUDAS, Enrique. 1984. "Múgica en la Revolución Mexicana". En VII Jornadas de Historia de Occidente. México: Centro de Estudios de la Revolución Mexicana.

CHÁVEZ, Daniar. 20i6. "La escuela socialista de la década de r930 y los procesos de interculturalidad del siglo XXI". Revista Estudios. Filosofía. Historia. Letras (II)): I69-I84.

GALEANA, Patricia. 2017. "Prólogo". En Francisco J. Múgica, el Constituyente de 1917. Daniar Chávez et al. México: Secretaría de Cultura del Estado de México.

HERNÁNDEZ, Jaime. I985. "El gobierno del general Francisco J. Múgica y la Universidad Michoacana de San Nicolás de Hidalgo". En VII Jornadas de Historia de Occidente, Francisco J. Múgica. México: Centro de Estudios de la Revolución Mexicana .

LATAPÍ, Pablo. 1992. "El pensamiento educativo de Jaime Torres Bodet: una apreciación crítica". Revista Latinoamericana de Estudios Educativos XXII(3): I3-44. 
MARÍA Y CAMPOS, Armando de. 1984. Múgica, crónica biográfica. México: Universidad Juárez Autónoma de Tabasco.

MARTÍNEZ-ASSAD, Carlos. 2004. El laboratorio de la revolución. El Tabasco garridista. México: Fondo de Cultura Económica.

MOCTEZUMA-BARRAGÁN, Javier. 20or. Francisco J. Múgica, un romántico rebelde. México: Fondo de Cultura Económica.

MONTES DE OCA, Elvia. 2009. "La escuela racionalista. Una propuesta teórica metodológica para la escuela mexicana de los años veinte del siglo pasado". http://www.uaemex.mx/plin/colmena/Colmena4I/Colmenario/Elvia.html (Fecha de consulta: 5 de octubre de 2017 ).

MÚGICA, Francisco. 1985. Hechos, no palabras... Tomos I y II. México: Instituto Nacional de Estudios Históricos de la Revolución Mexicana.

MUÑOZ, Juan. 1992. La educación en Tabasco. México: Gobierno del Estado de Tabasco.

NÚÑEZ, Enrique. 2016. Francisco José Múgica, gobernador de Tabasco (1915-1916). México: Gobierno del Estado de Tabasco.

QUINTANILLA, Susana. "La educación en México durante el periodo de Cárdenas (I934I940)". http://biblioweb.tic.unam.mx/diccionario/htm/articulos/sec_3I.htm (Fecha de consulta: 3 de octubre de 20I7).

RAMÍREZ, Rubén y Daniar CHÁVEZ . 20I8. "Educación y justicia en Francisco J. Múgica Velázquez: un michoacano en el trópico”. Revista Estudios. Filosofía. Historia. Letras XVI(I27) (invierno): II7-I35.

RODRÍGUEZ, María. I985. "Francisco J. Múgica y la educación en Michoacán i920-1922". En VII Jornadas de Historia de Occidente, Francisco J. Múgica. México: Centro de Estudios de la Revolución Mexicana.

TORRES, Trinidad. 20or. Mujeres y utopía, Tabasco garridista. México: Universidad Juárez Autónoma de Tabasco.

TORRES, Trinidad y Leticia ROMERO. I992. La educación de la mujer en Tabasco (de la Colonia al Porfiriato). México: Universidad Juárez Autónoma de Tabasco .

TORRUCO, Geney. 1988. Villahermosa, nuestra ciudad, Tomo II. México: H. Ayuntamiento del Municipio de Centro, Tabasco.

VALENZUELA, Georgette José. 2017. El Gral. Francisco J. Múgica, el llamado líder de las "izquierdas" en el Congreso Constituyente de 1916-1917. México: Suprema Corte de Justicia de la Nación. 
Notas

I La presente investigación documental procede en gran parte de los acervos bibliográficos de la familia Múgica, pertenecientes a la Biblioteca de la Unidad Académica de Estudios Regionales (UAER) de la Coordinación de Humanidades de la UNAM. Las imágenes, así mismo, pertenecen al Fondo Francisco J. Múgica, del Archivo Histórico de la UAER, y al Centro de Estudios de la Revolución Mexicana Lázaro Cárdenas A.C. Investigación realizada gracias al Programa UNAM-PAPIIT "Memoria y Archivo. Lázaro Cárdenas en la historiografía moderna. Un modelo de participación y divulgación del patrimonio documental de la UNAM en la Ciénega de Chapala", clave IA4004I9.

$2 \mathrm{Al}$ respecto, Patricia Galeana ha señalado que Múgica "encabezó [en el Constituyente] a los liberales radicales: los jacobinos, que fueron los que retomaron las propuestas del liberalismo social decimonónico. Las ideas de Ponciano Arriaga e Ignacio Ramírez, que habían quedado pendientes en la Constitución de I857, fueron incluidas en el artículo 27 [... ]. Múgica fue para la Constitución de i917, lo que Arriaga a la de i857. Su acción fue definitiva en los principales artículos: 3, 27 у г23 [... ]. En estos artículos se dio respuesta a las demandas sociales de la Revolución. Se reconoció personalidad jurídica a la propiedad de las comunidades indígenas y se dio la legislación laboral con mayores garantías de su época en el mundo" (Galeana 20I7. $7-9)$.

3 Archivo Histórico de la UAER. Fondo Francisco J. Múgica, sección Tomos, caja I, tomo I, doc. 282 , decreto iıi.

4 Archivo Histórico de la UAER. Fondo Francisco J. Múgica, sección Tomos, caja I, tomo I, doc. 282, decreto in. La formación que Múgica obtuvo en el Seminario de Zamora sufrió una transformación radical. La revisión de una de sus bibliotecas, la perteneciente al acervo histórico de la Unidad Académica de Estudios Regionales de la Coordinación de Humanidades de la Universidad Nacional Autónoma de México en Jiquilpan, Michoacán, nos permitió ubicar una pléyade de materiales bibliográficos que muestran el interés de Múgica por algunos temas. Entre ellos, destaca una veintena de libros sobre la Revolución, otro tanto sobre el Ejército y la táctica militar, los problemas agrícolas y el petróleo. En el campo ideológico-político destacan materiales sobre el pensamiento de V. I. Lenin. Contiene también una veintena de materiales sobre educación rural socialista, dentro de los cuales destaca un trabajo de Antón Makárenko, precursor de la escuela colectivista y de una pedagogía activa que proponía estrechar el trabajo intelectual y manual. En suma, la biblioteca alberga un amplio acervo que muestra las afinidades y aficiones literarias de Múgica y permiten entender su pensamiento transformador.

5 No obstante a esta visión optimista, durante el gobierno del general Calles, y durante los años de la persecución religiosa (I926-1929), también surgiría una gran desilusión hacia la educación que proveía el Estado, pues, los sectores más conservadores consideraban que el Estado se entrometía en el derecho legítimo de los padres para educar a sus hijos; a partir de ahí y hasta la administración de Lázaro Cárdenas (I934-1940), y bajo la denominada educación 
socialista que impulsó su gobierno, "la educación extraescolar en familias católicas comenzó a rivalizar y a combatir las enseñanzas oficiales" (Arce 2006, I47).

6 Una evaluación previa a esta temática puede consultarse en Rubén Darío Ramírez y Daniar Chávez, "Educación y justicia social en Francisco J. Múgica Velázquez: Un michoacano en el trópico", Revista Estudios. Filosofía. Historia. Letras XVI(I27) (invierno 2018): II7-I35.

7 En materia de derecho laboral, Múgica también tuvo una participación activa en el Constituyente de 1917. Patricia Galeana recuerda que fue él quien "presentó una modificación al párrafo final del proyecto del artículo [se refiere al i23] de Carranza, que amplió la protección del trabajador: 'la jornada máxima de trabajo no excederá de ocho horas [... ] queda prohibido el trabajo nocturno en las industrias a los niños y las mujeres. Se establece como obligatorio el descanso hebdomadario" (Galeana 20I7, Io); además, la "inclusión de una nueva sección en la Constitución llamada 'Trabajo y bienestar social' bajo el título de artículo i2z, tuvo su origen al someterse a discusión el i2 de diciembre de i9i6 el dictamen del artículo $5^{\circ}$, del proyecto del Primer Jefe, que era casi igual al de la Constitución de I857" (José 2017, 85), como miembro de la Primera Comisión, Múgica tendría también un papel destacado en la aprobación de los beneficios que poco a poco conquistaban los trabajadores.

$8 \mathrm{La}$ propuesta de la educación racionalista fue hecha por el barcelonés Francisco Ferrer Guardia a principios del siglo XX, que también fue conocida como nueva escuela. Comprendía nuevos principios pedagógicos que buscaban anular la influencia religiosa al momento que los estudiantes trataban de dar respuestas a sus cuestionamientos. En el garridismo, esta formación fue utilizada como herramienta para combatir también la influencia religiosa en la educación (Montes de Oca 2009).

9 Posteriormente Ignacio Chávez ocuparía la rectoría de la Universidad Nacional Autónoma de México entre ig6r y ig66.

Io Para una revisión más profunda al conflicto denominado Guerra Cristera y sus repercusiones en la educación mexicana, consúltese Francisco Arce Gurza 2006 y Susana Quintanilla, http://biblioweb.tic.unam.mx/diccionario/htm/articulos/sec_zI.htm (Fecha de consulta: 3 de octubre de 2017).

\section{Daniar Chávez Jiménez}

Doctor en Letras por la Facultad de Filosofía y Letras de la UNAM, investigador asociado "C" de tiempo completo en la Unidad Académica de Estudios Regionales de la UNAM y profesor invitado en la Escuela Nacional de Estudios Superiores de Morelia de la misma institución. Líneas de investigación: Patrimonio documental y Archivo. Gestión local y acceso a la información. Pertenece al Sistema Nacional de Investigadores. Ha coordinado libros como: Mester de Nomadía. Viajeros hispanoamericanos (1795-2011) (2019) y Rupturas y continuidades (2019). En el ámbito del desarrollo cultural en espacios rurales, coordinó el volumen: Comunidad y territorio. El caso del occidente michoacano (2019). Es también director de la Colección Sociedad y Estudios Regionales de la UNAM. 


\section{Rubén Darío Ramírez Sánchez}

Doctor en Ciencias Sociales, Especialidad en Estudios Rurales por El Colegio de Michoacán, investigador asociado "C" de tiempo completo en la Unidad Académica de Estudios Regionales de la UNAM. Líneas de Investigación: Conformación del Estado, violencia y transición democrática. Proyectos educativos de educación popular y complejidades de la universidad pública. Recientemente ha publicado: "Del edén al infierno: inseguridad y construcción del Estado en Tabasco". LiminaR. Estudios Sociales y Humanísticos XVII(2) (2019); "Transición en el pantano: elecciones extraordinarias y cultura política en Tabasco". El Cotidiano (216) (2019); "Conflictos regionales y Estado en el Occidente michoacano". En Comunidad y Territorio: El caso del Occidente michoacano. Daniar Chávez Jiménez y Teodoro Aguilar Ortega. México: UNAM, 2019 . 